\title{
Neologismos em De Gestis Mendi de Saa
}

\author{
JOÃO BORTOLANZA \\ Universidade Federal de Mato Grosso do Sul \\ Campus de Dourados
}

\begin{abstract}
RESUMO: Este artigo é o resultado parcial de minha pesquisa sobre o Lexicon do poema épico, o primeiro das Américas, De Gestis Mendi de Saa (1563), de Anchieta. O aspecto considerado são os neologismos empregados neste poema, para realizar um dos glossários do Lexicon Concordantiarum, objetivo de minha pesquisa. Neste trabalho, apresento os neologismos referentes a animais característicos, às armas de fogo e à Gens Brasillica: seus utensílios, seu habitat e outros aspectos de sua cultura. O objetivo é analisar o latim de Anchieta, sua habilidade em criar perífrases, com uma adjetivação precisa, para significar as novas realidades, em criar neonímias ou em atribuir novos semas aos vocábulos clássicos. Excelente humanista, Anchieta soube transmitir o novo na língua universal com muita propriedade.
\end{abstract}

PALAVRAS-CHAVE: Neologismos; Gens Brasillica; armas de fogo.

Pretendo apresentar o resultado parcial de minha pesquisa sobre o Lexicon do poema épico De Gestis Mendi de Saa, do Padre José de Anchieta. Exímio latinista, Anchieta soube lidar com as novas realidades, criando novos termos ou dando novas acepções a termos já consagrados, e isto com uma naturalidade e fluência invejáveis. Em pleno século XVI, vivendo no exótico Novo Mundo, o Humanista manteve o tom clássico, no estilo grandiloqüente das epopéias, ao descrever a nova Terra, fauna e flora, o esplendor da natureza tropical, com o encantamento de quem queria mostrar ao Velho Mundo - na língua universal de civilização da época - esta Terra Brasillis e esta estranha Gens Brasillica. O vocabulário precisava reciclar-se ante tanta novidade.

Atenho-me aqui apenas aos neologismos referentes às novas armas e aos indígenas, incluindo também as poucas ocorrências relativas à fauna brasílica.

\section{Armas de fogo}

Como poema épico, De Gestis vai mostrar o herói Mem de Sá a cometer façanhas, enfrentando viagens e guerras, a exemplo de Enéias, na Eneida. Nessas novas guerras, novas armas, desconhecidas dos romanos, vão exigir habilidade do épico: a pólvora, o fuzil, o canhão e todas as armas de fogo, com os pelouros, os tiros e a sua retumbante ação destruidora. 


\subsection{Pólvora}

A pólvora é sem dúvida o novo elemento por excelência de todo arsenal bélico dos novos cruzados da Fé e Império, em sua ação colonizadora/catequizadora, a demonstrar a superioridade frente à barbara gens munida de primitivos arco e flecha. E ante a falta da pólvora dos portugueses, operar-se-ão os mirabilia, pela intervenção divina, a incutir o medo entre os heréticos com farta munição e abundância de pólvora, levando-os à fuga covarde (v. 2810-48). Encontra-se no livro IV do poema - e justamente no momento em que se vive a apreensão de sua carência - uma bela definição de pólvora, sem precisar criar novos termos:

...pulvis, quem vivo sulphure et atro

Carbone ac nitro docti multo igne laborat

Artificis manus, ardenti qui pabula flammae

Sufficit, et magnis vulcanum viribus auget ${ }^{1}$.

Termos latinos passam a trazer o novo sema de "pólvora". São ignis ${ }^{2}$ potens ou edax, flamma sulphurea ou vorax, pulvis sulphureus ou mesmo simplesmente sulphura atra. Os adjetivos edax e vorax traduzem bem a ação rápida e destruidora da pólvora, sempre associada ao fogo e à negra (atra) fumaça do enxofre.

Enquanto faísca explosiva, Sulphureus parvo correptus lumine pulvis / dessilit, atque ruens rapido cita turbine flamma / occupat incautos... (v. 2380-2), embora partindo de um simples lampejo, transforma-se em turbilhão de fogo devorador. É esse pó que alimenta a chama, donde emana sua "ira", isto é, seu impetuoso poder de extermínio contra o inimigo: Pulvis qui pabula flammae / sufficit, unde iras concipit ignis edax (v. 29-30).

\subsection{Canhão}

A máquina de guerra, índice do poder do herói nas gestas da colonização, é, com sua imponência e seu ribombo aterrador, o canhão, com suas variantes que vão desde o curto morteiro ao longo falcão e à bombarda.

Dois termos latinos empregados para as antigas "máquinas de guerra", machina e tormentum, habilmente acompanhados de adjetivos a indicarem seu gigantismo e sua composição, empregam-se usualmente: vasta $(26,2378)$, aerea (2621), ingens (2634) e horrens machina; aerea tormenta rotata $(2665)$, aerea $(2718,2920)$ e bellica $(2027,2429)$ tormenta, ou simplesmente rotati (2642), subentendendo tormenti; ou simplesmente aerea fusa (2759), os "bronzes fundidos", como metonímia.

Veja-se, por exemplo este excerto, a destacar o fragor e a fumaça característicos, associados ao fogo da explosão:

\section{Tormenta horrificas vomuerunt bellica flammas \\ Et saevum tonuere: petit niger aethera fumus (2027-28).}

Acresça-se o emprego de molis vasta, imensa e tão pesada (immania pondera), nesta quase definição: 
... tormenta trahuntur

Aerea: ferratae vasta sub mole gemiscunt

Horrifico stridore rotae; vix lembus ad ipsas

Subsidens perfert immania pondera naves ${ }^{3}$ (2920-23).

Se nos anteriores houve deslocamento semântico, dois neologismos propriamente ditos figuram no poema épico anchietano, ambos amplamente definidos: bombarda (via francês bombarde) e falco (em Latim a significar apenas a ave de rapina); bombarda (2571, 2644) ferrea (2558) vem definida nos versos 2644-49:

... bombarda, ex fulvo fabricata metallo,

Ferratis innixa rotis, quae grandia vasto

Saxa vomens ore et conflata volumina, puppes

Ictibus infestat crebris impune, latusque

Rumpit utrumque, forat malos, tabulasque fragore

Comminuit diro ${ }^{4}$.

O falco $\left(2659^{5}\right)$ vem descrito nos versos $2615-19$

Falconem clamore vehunt [...] locatus

Vertice, jam saevo flammas vomit ore coruscas

Ignitosque globos, saxo constructa lacessens

Tecta; domum penetrant jam ferrea tela, ruuntque

Ligna $^{6}$.

\subsection{Fuzil}

Há uma única ocorrência dessa arma no poema, e o Autor emprega o adjetivo fusile (de fusilis = fundido, feito de metal fundido) na lexia composta ferrum fusile (421).

\subsection{Projéteis, pelouros, balas, tiros}

Telum, que, além de referir-se a toda arma de arremesso, se empregava na expressão tela trisulca lovis (Ovídio) para designar o terrível raio de Júpiter, é o vocábulo preferido por Anchieta para referir-se aos vários novos projéteis das armas de fogo, ocorrendo também freqüentemente para nomear os objetos tradicionais, no caso as setas dos indígenas. Mais uma vez, vai ser a presença da adjetivação que apontará para os novos significados: plumbea (24), flammantia (2621), ferrea (2618), ignea (2659), ignita (2899) tela; tela creberrima (439); tela minantia letum (1977); tela coruscis ignibus (2716); flammantibus telis (2919); horrificis telis (2634); jaculari tela coruscis ignibus (2716).

Glans já era empregada pelos clássicos com o sentido de bala de chumbo ou de barro cozido, o que permitiu sem dificuldade a Anchieta associar a nova carga semântica nestas duas ocorrências: ignita glande (2685); glandes horrisonas (421). 
Globus e pila, que em Latim tinham as acepções de bola e esfera, ampliam seu significado e passam a ser empregados com o sentido de bala ou projétil de arma de fogo: ignitos(2616), saevos (26) globos; crebris globis (389); crebrasque sonanti aere pilas (2619); flammantia saxa globosque (2635).

Mais criativas são as neonímias conflata volumina (2644) e conflatum plumbum (2694), a designarem as balas de ferro ou de chumbo. O adjetivo conflatus, com a acepção de "fundido, feito de metal fundido", associou-se facilmente a plumbum e a volumen ("objeto enrolado ou redondo"), criando expressões que não estranhariam aos clássicos, embora referindo-se a outras realidades.

A presença da pólvora, com seu sema "fogo", volta a empregar ignis e flamma, agora a designarem os projéteis das armas de fogo: coruscos (2377), acres (2772) ignes; crebris ignibus (2637); rapido cita turbine flamma (2381); horrificas flammas (2027); flammasque voraces (2834). As grossas pedras arremessadas pela artilharia pesada da época faziam-se acompanhar da pólvora em chama: flammantia saxa globosque (2635).

De se estranhar que ictus, na acepção de "tiro, disparo de arma de fogo", tenha tido apenas uma ocorrência em todo o poema - crebris ictibus (2647) - já que a ampliação semântica soa natural.

\subsection{Munição (artilharia, armas de fogo)}

Soa natural o emprego de termos latinos para o novo arsenal de ataque e destruição do século XVI, às vezes pela simples adição de qualificativos: stridentia arma (as barulhentas armas de fogo (445), splendentibus (2333), fulgentibus armis (2579); outras vezes empregando novamente telum com a nova acepção de "munição, armamentos": telorum copia magna (2428), maximus telorum numerus (2874); e, finalmente, voltando a empregar o adjetivo conflatus como no item supra, agora atribuído a metallum: alta domus, multo conflato armata metallo (2555).

\section{Fauna Brasílica}

São poucas as referências a animais típicos do Brasil, mas quando o faz, é com a naturalidade de um clássico, como quando se refere às araras e papagaios: pictasque volucres / humanos et quae referunt animalia gestus (2319-20), "as aves variegadas e os animais que imitam as maneiras humanas".

O caititu ou cateto é o spumiferus sus (322), também definido pelo sema do adjetivo habilmente incorporado ao nome para formar uma lexia nova, a imitar o nosso "porco-domato". Já a anta passa a exigir um esforço maior: a pele de anta, empregada pelo índio como escudo, é designada de alcinum tergus (1810). É um adjetivo derivado de Alces (alcis), que o Padre Armando Cardoso traduziu por "de anta", mas que poderia ser entendido como "de alce". De qualquer forma, em Latim o termo referia-se a outro tipo de animal ("quadrúpede semelhante a um asno").

Em duas comparações, tão ao gosto da épica virgiliana, aparece a onça: 
Ut cum saeva tigris, quam multa insania edendi

Collecta ex longo subigit, caligine noctis

Fisa, subit cratem obscuram, quam pondere magno

Grandia ligna gravem reddunt, stat territus ultra

Inclusus septo canis et religatus ad escam;

Haec, stimulata fame et praesentis imagine praedae,

Ingreditur, ventrem catulo pastura perempto,

Atque sitim exhausto pulsura cruore; sed illa

Introeunte, cadit lignorum machina grandis,

Immani rabidam prosternens pondere tigrim!

Sic saevi insidiis hostes cecidere subacti ${ }^{7}$ (1514-24).

Toda a cena, rica em detalhes típicos da caça à onça, flui em um Latim clássico, como se estivera a referir-se a realidades do Velho Mundo e do Império Romano. Mais do que o termo tigris, aqui sem dúvida em outra acepção, o que impressiona é a característica armadilha, a que não escapa a astuta onça, figura dos índios de Ilhéus, vencidos pela argúcia do Herói colonizador.

Ainda a onça, desta vez com seus filhotes, serve de imagem telúrica para a hesitação dos índios de Paraguaçu em entregar ao Governador os canibais que tinham acabado de fartar-se da carne de três cristãos:

Qualis foeta tigris, quam multis agmina telis

Venantum cingunt, foetus raptura tenellos,

Nec metus armorum letique instantis imago

Sistendi dat dira locum; nec pectus amorque

Maternus patitur catulis dare terga relictis ${ }^{8}$ (1780-84).

Novamente a onça é tigris com seus catuli ("filhotes de brutos") ou fetus ("fetos" ou, neste caso, "filhotes" - o texto registra foetus), e a cena, feito um quadro, um instantâneo, desenha-se com toda a naturalidade, apesar do novo.

\section{Gens Brasillica}

Extensa é a lista de "brasileirismos" referentes aos indígenas, ao seu habitat, a seus adereços, costumes ("vícios" para o Pe. Anchieta), instrumentos que se poderiam apresentar aqui - tudo aquilo que poderia ser chamado de exótico e fruto de encantamento para o europeu e, portanto, digno de figurar neste poema épico, que não deixa de ser também "Literatura de Informação" dos primórdios do Período Colonial -, mas limitar-me-ei a alguns representativos.

Partindo do rubra ligna (2317), a designar o pau-brasil, citado não como o primeiro ciclo econômico, mas como produto de troca dos franceses para com os índios - dele extrairiam a tintura para o corpo -, sem dúvida o que mais encanta é a figura do indígena: 
Ipsi jam picti diversicoloribus omnes

Incedunt pennis; pexis pars crinibus haeret,

Pars velut armillae validos cinxere lacertos,

Pars caput in speciem circumdat facta coronae

Arte laboratae mira - pallentibus albae,

Purpureis virides sunt mixtae - forma nitescit

Discolor; ex labiis pendent aut alba foratis

Marmora, vel virides nitido splendore lapilli ${ }^{9}$ (1640-47).

Parece haver uma preocupação de Anchieta em vestir o índio nu, desviando a atenção para os adereços, sobretudo as penas de diversas cores, transformadas em "cocares" pennis diversicoloribus ... pars caput in speciem circundat facta coronae arte laboratae mira - enfiadas nos cabelos bem penteados - pexis crinibus pars haeret - ou a circundar os braços e pernas, feito braceletes - velut armillae ("braceletes"). Ao carnavalesco das cores - diversicoloribus pennis... forma nitescit discolor - somam-se os bem mais exóticos (e estranhos!) "botoques" ou "tembetás" a penderem dos lábios perfurados - ex labiis foratis pendent alba marmora vel virides lapilli. O quadro ficaria completo se the emendássemos o excerto abaixo, em que os índios omnes vestiti patrio robusta colore membra ("vestidos!" com as cores da tribo) et picto veras imitantes corpore vestes (nudez disfarçada!), assim são pela primeria vez descritos no poema:

Omnes vestiti patrio robusta colore

Membra: genas illi et frontem mediasque rubenti

Turparunt suras; hi nigro corpora sulco

Pingentes totos diversis nexibus artus,

Et picto veras imitantes corpore vestes [...]

Pectora centum alii variarum ac terga volucrum

Nudarunt pinnis, quas infecere colore

Diverso, aptantes visco lita corpora circum;

Ornarunt alis avium capita ardua multi,

Plurima pendentes pexo redimicula crine ${ }^{10}$ (326-330 e 334-338).

O aparente ar de encantamento do Jesuíta trai-se no emprego de turparunt ("enfearam, tornaram medonho, desfiguraram") e se revela em todo o subjetivo nos dois versos seguintes: Atque alios aliosque habitus per nuda dedere / Membra feri, horribiles visu, vultuque minaces - "Com estes e muitos outros adereços, medonhos e feios, / cobrem os membros nus os selvagens ferozes." Nada, porém, desmerece o colorido do estilo, a propriedade do Aedo na pintura do Indígena.

O índio, com seus instrumentos característicos, irradia sua cor local, apesar do olhar recriminador do Poeta, hábil, porém, em forjar os novos termos. Ora é o "tacape" - lignaque picta avium pennis (321), fero ligno (1564), dipictaque ligna (2203) ou, mais descritiva- 
mente, ligna fabricata atque arte polita, diversis circum pennis redimita volucrum, queis mandenda solent confringere tempora captis" (1637-9). O "cauim", a causa de todos os males, a origem de todos os "vícios", na visão de Anchieta, é o vinum, ou vina no plural, posto que podia ser preparado com caju ou outras frutas, com mandioca e milho mastigados. vinum (1120), potata vina (1124), his vinis (1135), spumantia vina (2156) ou mesmo Lyaeo (933), vem assim descrito nos versos 1120 a 1135, de que destaco os referentes ao fabrico e ao julgamento implacável de Anchieta:

\author{
Quo femina more \\ Porrigere assuevit lasciva pocula dextra! \\ Impletum exonerant stomachum, potata vomentes \\ Vina; bibunt iterum pleno de ventre vomenda... (1122-25) \\ ... mala denique cuncta \\ Patrandi sopitus amor jamjamque senescens \\ His expergisci et veluti juvenescere vinis ${ }^{12}$ (1133-5).
}

Os instrumentos musicais são as "cabaças com canudos espetados" - curvata cucurbita inserta oblongis calamis resonantibus (411) - ou os "búzios" ou "(u)atapus", estes, dada a sua origem, são as "conchas" ou "caracóis" - cochleas sinuosas, como se pode verificar nestes versos, tendo no último hemistíquio o estranhamento do Jesuíta e europeu Anchieta ("tais são as trombetas desta feroz gente!"):

His edit raucos curvata cucurbita cantus,

Inserta oblongis calamis resonantibus; illi

Horrendum cochleas sinuosas flatibus implent,

Et saevum reboant; - ea dirae classica gentis! ${ }^{13}$ (411-14)

Habitat desta barbara natio, suas ocas e tabas assim vêm designadas por Anchieta:

a) Ocas: Fumosa (867), fumantia (1036) tecta - tectis (1861), atra tecta multum fumum eructantia (2154), congestasque casas paleis (1037), domos (1903, 1954), domos infidas (2210), infidas in aedes (2197) e occiduas ad aedes (2307). Como se pode ver, é a qualificação, outra vez, que carrega termos clássicos de novos semas, do metonímico tectum, passando pelo mais apropriado casa, aos (irônicos!) domus e aedes. De se estranhar que não tenha empregado tugurium. O que chama a atenção é a associação da oca com a fumaça: sempre pelo olhar crítico de Anchieta.

b) Tabas: oppida quattuor amplo circuitu (1043), in quattuor ampla coactos oppida (1052), a designarem as novas aldeias ou reduções; oppida (494, 2201, 2307, 2358), centum oppida bisque triginta (1953), omnia strata oppida (2055), as duas últimas referentes às aldeias ou tabas destruídas, as grandes gestas do Herói colonizador. E finalmente multos pagos (2306). Só o contexto externo é que pode identificar os novos semas com que se empregam os termos latinos. 
O pajé, contra quem Anchieta não poupa vitupérios, uma vez que "novos pajés", os sacerdotes jesuítas, deverão ocupar-lhe o lugar, como resultado da Cruzada da Fé e Império cantada nesta epopéia, vem nomeado como perverse venefice (1142). Nos versos de 1141 a 1155 , este caráter de feiticeiro mal-intencionado, enganador de crédulos - vetus fraus - vem descrito sobejamente:

Non posthac paleam, multove volumine filum

Collectum ostendes aegro ${ }^{14}(1150)$.

Vides qualem languenti e corpore morbum nunc tibi sugendo extraxi? ${ }^{15}$ (1152)

Jam tibi nulla tuis utendi audacia technis ${ }^{16}$ (1141).

Acresça-se este elucidativo excerto:

... Jam non languentia morbo

Membra fricare licet manibus mendacibus; artus

Aut suxisse labris impuris, quos mala vexant

Frigora, vel febris nimio inflammata calore

Viscera, vel podagras lentas tumidosque lienes.

Non ultra suges illudens fraudibus aegros ${ }^{17}$ (1143-48).

Concluindo, reafirmo, com esta pequena parte de meu levantamento, que os neologismos inserem-se com fluência e propriedade no texto clássico latino de Anchieta. Muitas são as novas realidades a serem nomeadas, muitas delas já em uso dos Humanistas portugueses da Universidade de Coimbra, onde consolidou sua formação clássica, mas há todo um mundo novo, novos habitantes, nova fauna e flora, nova geografia e novo clima, toda uma natureza tropical a "encantar", pelo que tem de exótico, todo um material precioso para ser vazado na língua universal da época. E o latim do De Gestis Mendi de Saa, com suas perífrases, ampliações semânticas, novas lexias e neonímias, mantém-se clássico, fluente e próprio, em que pese a farta adjetivação empregada.

\section{Notas}

1 - “... pó, que a mão do destro operário fabrica de vivo enxofre, de negro carvão e de nitro, em grande fornalha, pó que alimenta a chama furiosa e aumenta de muito o poder desse elemento". A tradução, nesta comunicação, é sempre do Pe. Armando Cardoso.

2 -Ubicam-se as ocorrências: potens ignis (24), ignis edax (30, 390), flamma (2429), flamma vorax (422), sulphurea flamma (439), sulphura atra (422), sulphureus pulvis (2380).

3 - "Os canhões em salva vomitaram tiros horrendos/ com ribombo medonho, enchendo o céu de fumaça" [...] "E arrastam/ os canhões [...] Gemem sob a massa enorme as rodas de ferro/ com horrendo ruído: o batel que as acolhe/ mal pode levar aos navios esses pesos gigantes." 
4 - "... uma bombarda de metal amarelo/ sobre rodas de ferro. Da boca enorme, o monstro arrota$\mathrm{va/}$ penhascos e balas de metal, molestando à vontade/ com tiros contínuos as naus: fere as popas e arromba/ um e outro flanco, estilhaça mastros e pranchas/ com fragor espantoso."

5 - Os números entre parênteses referem-se aos versos do De Gestis.

6 - "Entre gritos (possantes) arrastam o falcão [...] postado/ no cume a vomitar incêndios, da boca tremenda,/ e a arrojar pelouros, forçando a cantaria das casas./ Já as balas de ferro arrombam a casa e os madeiros/ se desmoronam".

7 - "Como quando a onça feroz, subjugada atrozmente/ por fome de vários dias, confiada nas sombras da noite,/ penetra sob escura grade, que grandes troncos massudos/ tornam pesada. Estarrece do outro lado tremendo/ o cão preso num cercado e amarrado para negaça./ A onça, picada da fome e da imagem da preia presente,/ avança para rasgar-lhe as carnes e cevar-se com elas/ e desalterar-se no jorro do sangue: mas então de repente/ a malha enorme de troncos desaba-lhe em cima/ e com o peso imenso a imprensa no chão, enraivada./ Assim caíram os inimigos vencidos pela cilada." Na tradução de Cardoso, onça aparece como tigre, por isso meu grifo.

8 - "Assim à onça parida acossam com inúmeros dardos/ os caçadores que lhe vão roubar os filhotes:/ nem o medo das armas, nem a cruel perspectiva da morte/ lhe permitem parar um momento, nem a ânsia materna/ lhe consente a fuga do posto e o abandono do ninho."

9 - "Todos eles vêm pintados de variegada plumagem/ que em parte se fixa ao penteado de longos cabelos;/ parte, a modo de pulseiras, cinge os membros robustos;/ parte, em forma de coroa, com grande arte disposta,/ lhes circunda a cabeça. Entremeiam-se às brancas/ as penas amarelas, às vermelhas as verdes e todo o conjunto/ brilha pela variedade. Alvos pedaços de mármore pendem/ dos lábios furados ou verdes pedrinhas de vívido brilho."

10 - "Pintam os membros robustos/ com as cores da tribo; tingem ("enfeiam, desfiguram") com listas vermelhas/ as faces, a fronte e as meias pernas; o resto do corpo/ com riscas pretas, tão bem enlaçadas, membro por membro. [...]/ Outros depenam o peito e as costas de inúmeras aves/ e tingindo-lhes as penas de variadíssimas cores/ colam-nas ao corpo, untado de visgo./ Outros ornam o topete com asas de pássaros/ e dependuram muitos enfeites dos penteados cabelos."

11 - "A direita empunha o tacape, trabalhado com arte e polido,/ ornado em derredor de penas de aves variadas:/ com ele os antropófagos rompem a cabeça aos cativos."

12 - "Que impudicos meneios / os das mulheres que oferecem as lascivas bebidas!/ Fartam de vinho o ventre, e, cheio, tudo vomitam,/ e bebem de novo e cheios aos vômitos tornam. [...] O desejo malvado/ de todos os crimes, sopitado e pouco a pouco envelhado,/ despertava e rejuvenescia ao ardor desses vinhos."

13 - "Uns a cabaça espetada de longos/ e reboantes canudos, tiram sons cavernosos./ Outros sopram horrendamente em búzios recurvos/ ecoando um som medonho: são os clarins dos selvagens" ("tais são as trombetas desta gente feroz!")

14 - "Não mais mostrarás ao doente palhas e fios compridos astuciosamente enrolados".

15 - "Vês que doença te tirei com meus lábios do corpo enfraquecido?"

16 - "Já não ousas agora servir-te de teus artifícios".

17 - "Já não podes com mãos mentirosas / esfregar membros doentes, nem com lábios imundos / chupar as partes do corpo que os frios terríveis / enregelaram, nem as vísceras que ardem de febre, / nem as lentas podagras nem os baços inchados. Já não enganarás com tuas artes os pobres enfermos..." 


\section{Referências bibliográficas}

ANCHIETA, Pe. José de. De Gestis Mendi de Saa. Introdução, versão e notas do Pe. Armando Cardoso. São Paulo: Edições Loyola, 1986.

FERREIRA, Aurélio B. de H. Novo Aurélio Século XXI: o dicionário da Língua Portuguesa. $3^{\text {a }}$ ed. Rio de Janeiro: Nova Fronteira, 1999.

GAFFIOT, Félix. Dictionnaire Latin-Français. Paris, Hachette, s/d.

SARAIVA, F. R. dos Santos. Novíssimo Dicionário Latino-Português. $11^{\text {a }}$ ed. Rio de Janeiro; Belo Horizonte: Garnier, 2000.

BORTOLANZA, João. Des néologismes dans le poème épique du Père Joseph d'Anchieta. Classica, São Paulo, 13/14, p. 383-392, 2000/2001.

RÉSUMÉ:Cet article est le résultat partiel de ma recherche sur le Lexicon du poème épique, le premier des Amériques, De Gestis Mendi de Saa (1563) d'Anchieta. L'aspect envisagé sont les néologismes employés dans ce poème, pour réaliser un des glossaires du Lexicon Concordantiarum, objectif de ma recherche. Dans ce travail, je présente les néologismes référés à des animaux caractéristiques, aux armes à feu et à la Gens Brasillica: leurs outils, leur habitat et et d'autres aspects de leur culture. Le but est analyser le Latin d'Anchieta, son habilité pour créer des périphrases, avec une adjectivation précise, pour signifier les nouvelles réalités; de créer des néonymes ou d'attribuer des nouveax sèmes aux vocabules classiques. Excellent Humaniste, Anchieta sut transmettre le nouveau dans la langue universelle avec beuacoup de propriété.

MOTS-CLÉS: Néologismes; Gens Brasillica; armes. 